\title{
Seasonal Variation of Some Atmospheric Parameters in Fresh Water Swamp and Sudan Savanna areas of Nigeria
}

\author{
F. O. Aweda ${ }^{1 *}$, J. O. Agbolade 2 , J.A. Oyewole 3 , M. Sanni ${ }^{4}$ \\ ${ }^{1,3}$ Physics and Solar Energy Programme, College of Agriculture Engineering and Science, Bowen University, Iwo, Osun State, NIGERIA. \\ ${ }^{2}$ Electrical and Electronic Department, Federal Polytechnic, Ede, Osun State, NIGERIA. \\ ${ }^{4}$ Department of Science Technology, Federal Polytechnic, Offa, Kwara State, NIGERIA.
}

\begin{abstract}
The year in year out variation in atmospheric parameters, solar radiation, and meteorological variables such as ambient temperature, relative humidity $\mathrm{RH}$, wind speed etc, are posies that can be and are used to describe the atmospheric conditions. Ten years of data obtained from the Nigerian Meteorological Agency (NiMet) was analysed. Results showed that solar radiation rises from January to get to its peak in April which is maintained till August before it begins to fall again with the Sudan savanna area (Maiduguri) having a value of (15.70 $\left.\mathrm{MJm}^{-2} \mathrm{month}^{-1}\right)$ and freshwater swamp area (Ikeja) having the value of $\left(10.16 \mathrm{MJm}^{-2} \mathrm{month}^{-1}\right)$. The extraterrestrial radiations calculated for the two stations are 333.53( MJm $^{-2}$ month $\left.^{-1}\right)$ and $195.53\left(\right.$ MJm $^{-2}$ month $\left.^{-1}\right)$ respectively. $^{2}$ However, the relative humidity of Ikeja (84.54\%) is higher as compared to that of Maiduguri (42.23\%). The minimum temperature ranges observed for the two stations varies from $(22-24)^{\circ} \mathrm{C}$ and $(12-26)^{\circ} \mathrm{C}$, while the maximum temperature was as high as $33^{\circ} \mathrm{C}$ and $40^{\circ} \mathrm{C}$ obtained in April for Ikeja and Maiduguri, respectively. Similarly, the average wind speed is higher for Ikeja (4.97m/s) than for Maiduguri $(4.62 \mathrm{~m} / \mathrm{s})$. The result of the statistical correlation reveals that, in Maiduguri, solar radiation was found to have a significant negative relationship with relative humidity $(r=-.256, p<0.01)$ and a significant positive relationship with minimum and maximum temperature ( $p<0.05)$. This means that minimum and maximum temperatures increase as solar radiation increases $(p<0.05)$. Relative humidity decreases as solar radiation increases. In Ikeja, solar radiation was found to have a significant negative relationship with relative humidity $(r=-.350, p<0.01)$ and wind speed $(r=-146, p<0.05)$ and significant positive relationship with minimum temperature $(r=.410, p<0.05)$ and maximum temperature $(r=.575, p<0.01)$. In conclusion, the variables like relative humidity, minimum temperature and wind speed are higher in the freshwater swamp area of Nigeria as compared to the Sudan savanna area, while the solar radiation, extraterrestrial radiation and maximum temperature are generally higher in the Sudan savanna area of Nigeria.
\end{abstract}

Keywords: Solar radiation, atmospheric parameters, seasonal radiation, sudan savanna, NiMet

\subsection{INTRODUCTION}

The seasonal variations of the atmospheric parameters are important in the study of atmospheric physics. Direct solar radiation and the ambient temperature of the air provide the necessary energy for the evaporation of water molecules on the surface of the earth [1]. Studies have shown that atmospheric weather parameters are of great importance in the study of atmospheric physics. [2] reported that weather is generally considered as the state of the atmosphere at a given time at any given location. It may also be referred to as the aspects of the atmospheric state which is visible and experienced because of human [3]. At high temperatures, there will be more evaporation across any region [4]. The weather conditions of any given location are often described in terms of the meteorological elements which include the state of the sky, temperature,

*Corresponding author (Tel: +234 (0) 803256 6053)

Email addresses: francisaweda@gmail.com (F. O. Aweda),yemilade2013@gmail.com (J. O. Agbolade), joeademola@gmail.com (J.A. Oyewole), sannimuhammed@yahoo.com (M. Sanni) winds, pressure, precipitation, and humidity. These factors initiate and influence atmospheric processes [5]. Solar radiation reaching the Earth's surface is the main source of energy for life on the planet, and solar radiation governs diverse surface processes such as evaporation, plant photosynthesis, the hydrological cycle, and the related terrestrial carbon cycle [6-7]. Accurate estimation of potential evapotranspiration is an important step for calculating crop water requirements under current and future climatic conditions, and various methods have been developed and compared with better estimate potential evapotranspiration [8]. As reported by [9], solar radiation is an essential input for those methods; however, if this input were not accurately quantified, the following performance comparison of different methods would be meaningless. The impacts of climate change on potential evapotranspiration have been widely assessed around the world [10-11], and accurately quantified solar radiation is expected to help better understand the contributions of different variables, such as temperature and relative humidity, to changes in potential evapotranspiration. 
Hence, accurate quantification of solar radiation is required for various practical applications, such as agricultural and water resource planning and management and the design of irrigation systems $\left[\begin{array}{lll}6 & \& & 12\end{array}\right]$. Furthermore, solar radiation is also the most fundamental renewable and clean energy source in nature and can serve as an alternative to fossil fuels. Therefore, knowledge of solar radiation is essential for the optimal design and evaluation of solar energy applications, such as photovoltaic and solar thermal systems [13-14]. [15] reported that solar radiation was the most sensitive meteorological factor affecting evaporation while wind speed was the least sensitive factor. [16], reported that the variations of surface water vapour density in four Nigerian stations showed that surface water vapour density is higher at night by an average of $9.9 \%$ than during the day in the southern stations while in the midland station of Minna, the reverse is the case. Observing seasonal variations of refractivity gradient in three climatic zones in Nigeria, [17] has found out that in each of the zones, the characteristic topographical features have a greater influence on refractivity gradient behaviour. But in this study, seasonal variation of atmospheric parameters comparison between Ikeja and Maiduguri will be more focused for solar energy applications.

Many authors have worked on solar radiation in the country, but to the best of our knowledge, none have worked on relating swamp freshwater area and Sudan Savanna area together. Therefore, for this research, we were motivated to evaluate the empirical models proposed by [18] as reported by [19] for the estimation of daily direct and a diffuse radiation of seasonal variation of some atmospheric parameters in freshwater swamp and Sudan Savanna areas of Nigeria, and then, the estimated direct and diffuse radiation was further used to calculate extraterrestrial radiation. The objectives of this study were to (1) determine the extraterrestrial radiation of the two stations by using the empirical models for the estimation of global, direct, and diffuse solar radiation collected from the NiMet and (2) to determine the variation in temperature, relative humidity and solar radiation of the two stations which will be helpful for researchers and engineers to better understand the variation in global solar radiation, as well as direct and diffuse solar radiation in the entire country.

\subsection{METHODOLOGY}

Monthly data of solar radiation, relative humidity, minimum and maximum temperature, and wind speed for the station under investigation were collected, for the period 2001 to 2010, from the Nigeria Meteorological Agency (NiMet) Oshodi, Lagos. From the data collected, it was observed that there are missing values. This missing data shows that there is no reading or there is machine error during the data collection. The missing data were sum to zero. The monthly mean of the parameters was determined by finding the average of all the parameters of each month in two stations under consideration. According to [3] and [20], the trend of the monotonic increase or decrease in average value between the beginning and the end of a time series. Meanwhile, the trends in climatic data are seldom linear ([21] and [22]), the linear regression method has been used to search for trends in many climatic time series (e.g. [5], [23], and [24]). Applying equations 1-3 to monthly values of parameters as recorded and collected from the Department of Meteorological services Oshodi from 2001 to 2010 , monthly values of the extraterrestrial radiations were computed for the two stations.

\subsection{Data Analysis}

Descriptive statistics were computed for each of the variables and the univariate relationship between the variables was examined using Pearson correlation. The effect of solar radiation on each of the variables $(\mathrm{RH}$, MinT, MaxT and wind speed) was examined using regression and a p-value less than 0.05 was considered statistically significant. Computation of results was facilitated using the Statistical Package for Social Sciences (SPSS version 20.0) and graphical representation of results was done in Microsoft Excel.

\subsection{Extraterrestrial radiation for monthly periods $\left(\boldsymbol{R}_{a}\right)$}

$R_{a}=\frac{24(60)}{\pi} G_{S c}\left[w_{S} \sin (\varphi) \sin (\delta)\right]+$

$\cos (\varphi) \cos ^{\pi}(\delta) \sin \left(w_{s}\right)$

$R_{a}=$ extraterrestrial radiation $\left(\mathrm{MJm}^{-2} \mathrm{month}^{-1}\right)$,
$G_{s c}=$ solar constant $\left.=0.0820 \mathrm{MJm}^{-2} \mathrm{~min}^{-1}\right)$
$d r=$ inverse relative distance Earth-Sun,
$\omega_{s}=$ sunset hour angle $(\mathrm{rad})$,
$\varphi=$ latitude (rad)
$\delta=$ solar declination $(\mathrm{rad})$

However, the giving expression show the values of solar declination with varying degree of accuracy which have been developed by several authors. Therefore, [18], presented the solar declination angle equation $\delta$, in degree as:

$$
\begin{aligned}
& \delta=(0.006918-0.399912 \cos \Gamma+0.070257 \sin \Gamma- \\
& 0.006758 \cos 2 \Gamma+0.000907 \sin 2 \Gamma- \\
& 0.002697 \cos 3 \Gamma+0.00148 \sin 3 \Gamma)\left(\frac{180}{\pi}\right)
\end{aligned}
$$

Thus, the equation estimates $\delta$ with a maximum error of $0.0006 \mathrm{rad}(<3)$.

$d_{r}=1+0.0033 \cos \left(\frac{2 \pi}{365} J\right)$ 
$J=$ day number in the year between 1 (1 January) and 365 or 366 (31 December), (at an average $d r=1.0330$ ). $w_{s}=\cos ^{-1}[-\tan (\varphi) \tan (\varphi)]$

Table 1.0: Average Julian day or day number $(\boldsymbol{J})$ and declination angle $(\boldsymbol{\delta})$ for the month of the year for both locations

\begin{tabular}{ccc}
\hline Month & Average J & Declination $\boldsymbol{\delta}$ \\
\hline January & 17 & -20 \\
February & 16 & -12.95 \\
March & 16 & -2.42 \\
April & 15 & 9.41 \\
May & 15 & 18.97 \\
June & 11 & 23.09 \\
July & 17 & 21.18 \\
August & 16 & 13.45 \\
September & 15 & 2.22 \\
October & 15 & -9.60 \\
November & 14 & -18.11 \\
December & 10 & -23.05 \\
\hline
\end{tabular}

\section{0}

\section{RESULTS AND DISCUSSION}

The variations of minimum temperature with months in Maiduguri and Ikeja Meteorological Stations shows that the minimum temperature in Ikeja throughout the study is constant except for the observed dip in August, which is a little, dry season period see Fig. A. This varied between $(22 \text { and } 24)^{\circ} \mathrm{C}$. However, the minimum temperature in Maiduguri has a wide range as compared with Ikeja.

The minimum temperature for Maiduguri over the years of study is $21.56^{\circ} \mathrm{C}$ with May $\left(25.60^{\circ} \mathrm{C}\right)$ being the highest, which exemplify the rainy season, while the least occurrence took place in December $\left(12.93^{\circ} \mathrm{C}\right)$ been the dry season. Ikeja has a minimum temperature $\left(21.56^{\circ} \mathrm{C}\right)$ with March $\left(24.09^{\circ} \mathrm{C}\right)$ being the highest and the last occurrence is in August $\left(21.71^{\circ} \mathrm{C}\right)$.

The study shows that the maximum temperatures of Maiduguri and Ikeja were quite different. Maiduguri has the highest maximum temperature in April $\left(>40^{\circ} \mathrm{C}\right)$ and lowest in August $\left(>31^{\circ} \mathrm{C}\right)$ while the highest maximum temperature in Ikeja Station was in February $\left(33.40^{\circ} \mathrm{C}\right)$. The lowest value was observed in July $\left(28.38^{\circ} \mathrm{C}\right)$. This implies that July and August are break periods.

Fig. $\mathrm{C}$ revealed that Maiduguri had the highest maximum temperature in April. While May, June, October, November, February, and September have a maximum temperature above the average. The Relative Humidity (RH) for Ikeja show a constant variation throughout the year except in February and March see Fig. E. While Maiduguri revealed a different variation that is, RH was maximum in August and fall astronomically. The relative humidity $(\mathrm{RH})$ for the two stations in the period of study was found to be $63.38 \%$ as shown in Fig. E. However, relative humidity in Maiduguri was generally below the average value with the least in September. With Ikeja the value $63.38 \%$ in all the months throughout the study.

Fig. G compares the solar radiation in the two locations. However, the pattern of variation over years was maintained. Radiation extent rose from January steadily and reaches the peak in April and then fall till August when the lowest value was recorded. There is a sharp increase from August to October. The same pattern holds for Ikeja, which have its lowest value in August $\left(6.77 \mathrm{MJm}^{-2} \mathrm{month}^{-1}\right)$. The average solar radiation in the two stations for the period of study was $12.95 \mathrm{MJm}^{-}$ ${ }^{2}$ month $^{-1}$. Maiduguri solar radiation was generally above the average with the highest value in March and April. Windspeed in Ikeja was high in all the months over the year of study than what was observed in Maiduguri. The highest windspeed occurred in August and October while the least was in November. The wind speed in Ikeja was $4.97 \mathrm{~m} / \mathrm{s}$, while in Maiduguri was $4.62 \mathrm{~m} / \mathrm{s}$. 

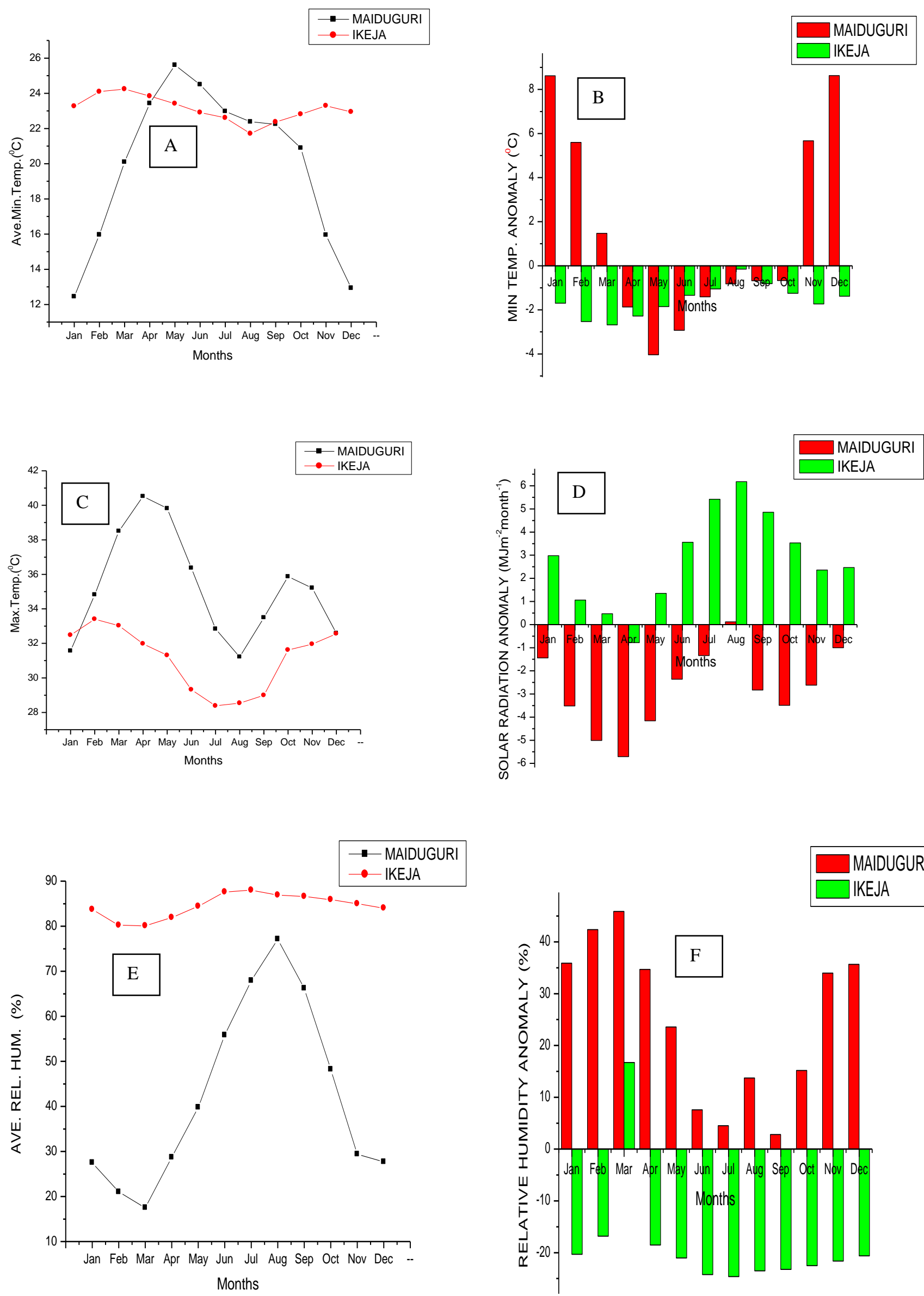

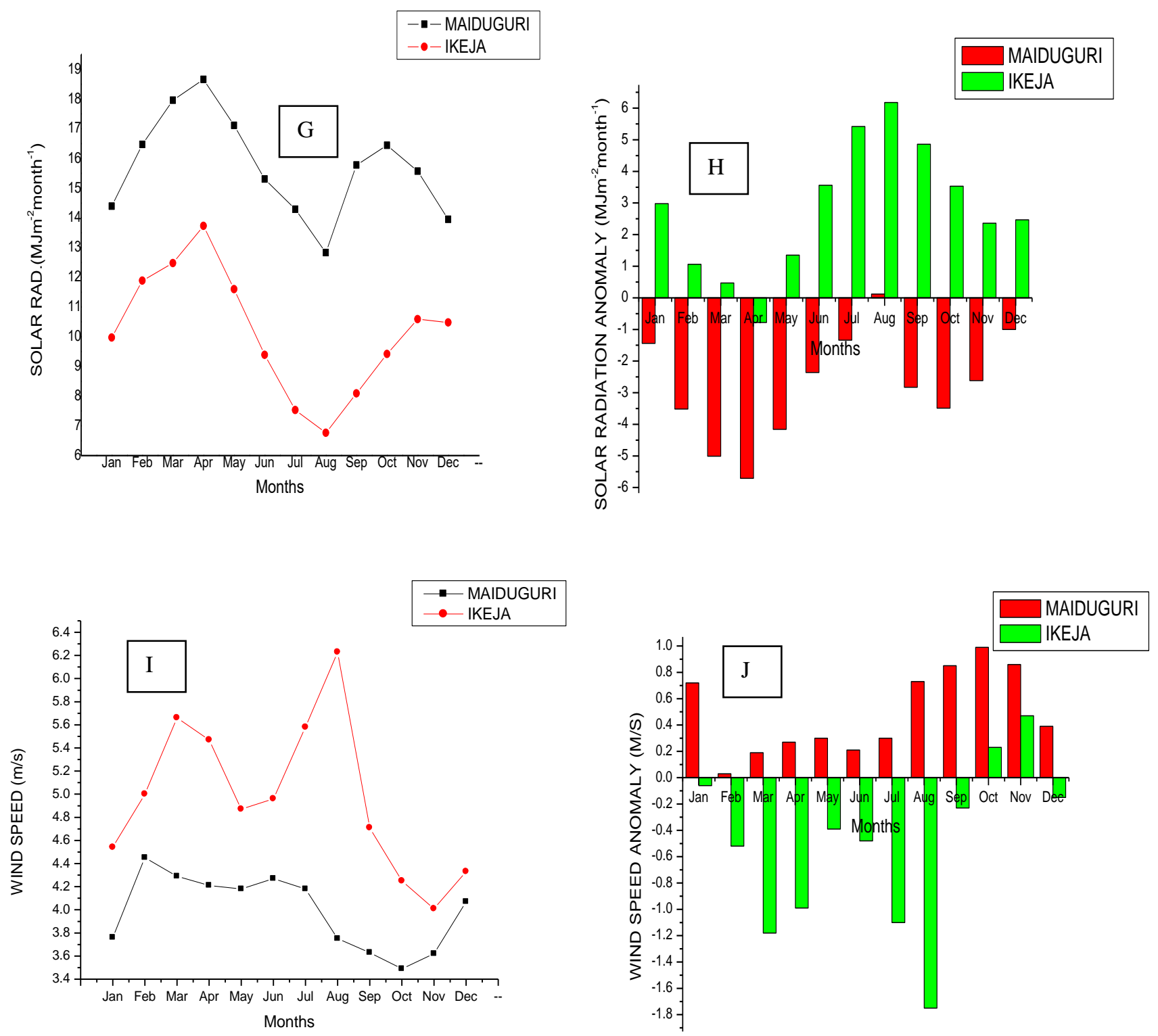

Figure 1: Variation of the selected atmospheric parameter of Sudan (Maiduguri) and freshwater swamp station (Ikeja)
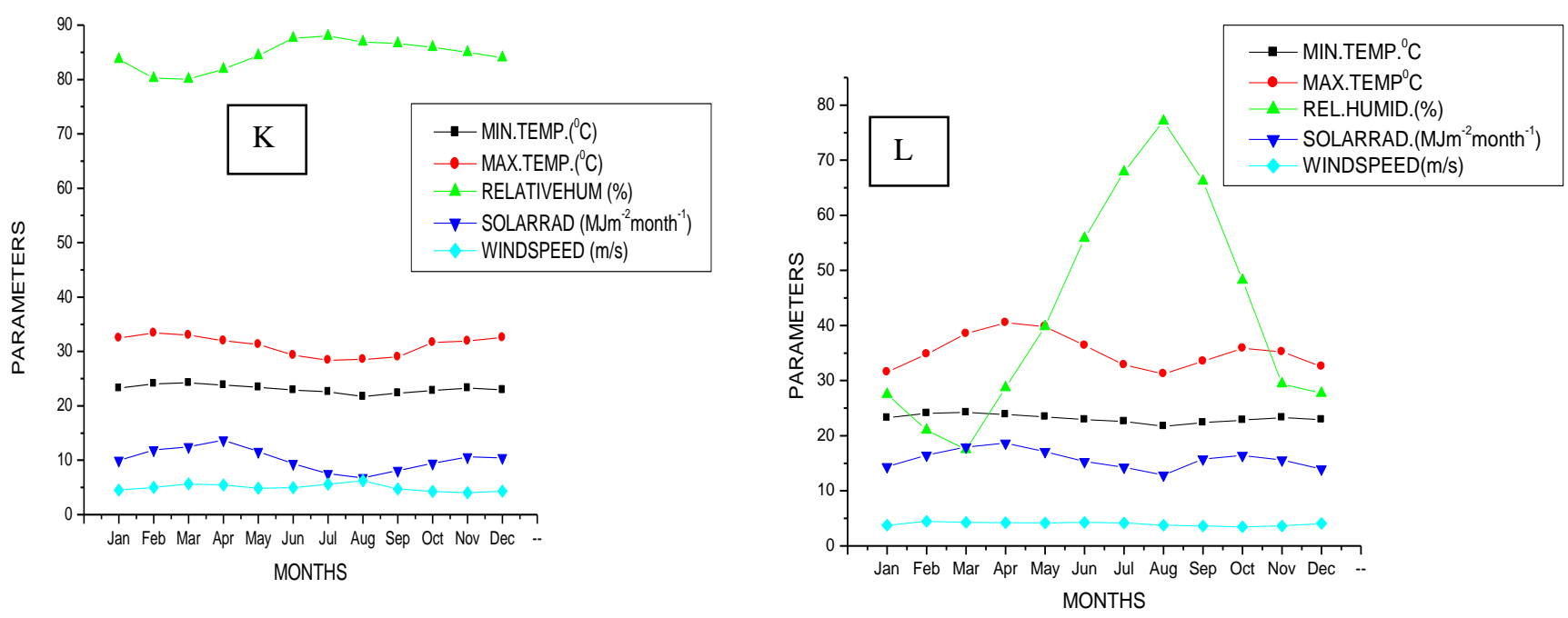

Figure 2: Variation of the average atmospheric parameters for Ikeja and Maiduguri 
Fig. $\mathrm{K}$ and $\mathrm{L}$ above show the variation of the parameters (minimum and maximum temperature, relative humidity, wind speed and solar radiation) for the two stations (Ikeja and Maiduguri). For Ikeja, it was observed that the parameters have the same pattern. July through September maximum temperature and solar radiation were at their minimum values. Wind speed and relative humidity were at their highest values. While minimum temperature appears steady all through with very little variation. Other parameters except relative humidity appear to increase from January to March.

Though the increase in solar radiation extends till April.
Fig. L shows that maximum temperature and solar radiation were at their lowest and highest values in August and April, respectively. Relative humidity was at its highest value in August and its lowest value in March. The relative humidity is at its lowest value in March. Fig B, D, $\mathrm{F}, \mathrm{H}$ and $\mathrm{J}$ show the anomaly of the variation of the parameters use in this study. It was observed that the anomaly for each location has distinct peaks which are synonymous to each of the parameter. The extraterrestrial radiation shows that Maiduguri has a higher value as compared with Ikeja. Both stations follow the same pattern as shown in Fig.3.With the highest value in June.

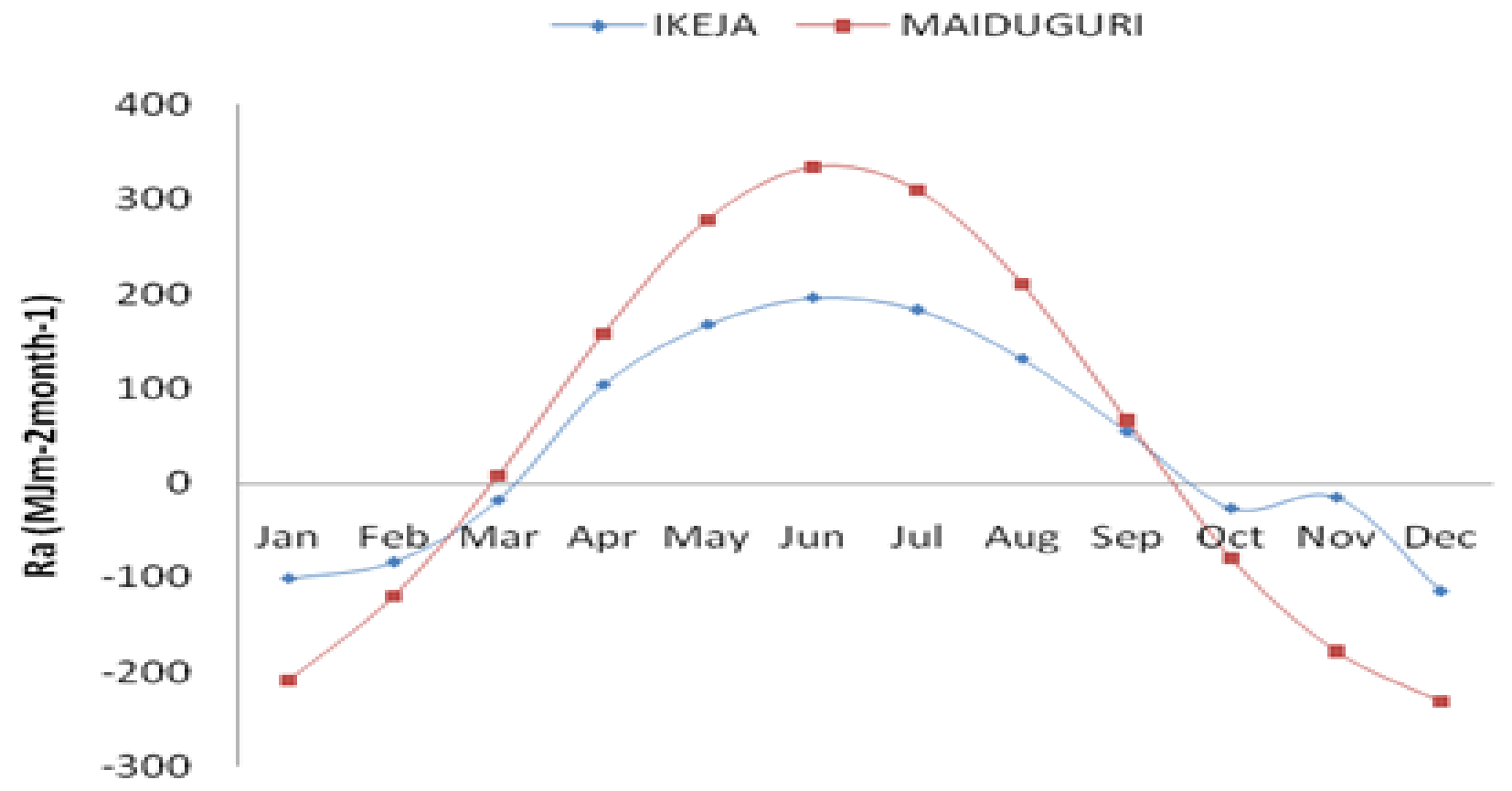

Figure 3: Extraterrestrial Radiation of Ikeja and Maiduguri

Maiduguri has a sharp increment while Ikeja has a low increment. According to [14], the position of the sun, the length of the day affect extraterrestrial radiation $\left(\mathrm{R}_{\mathrm{a}}\right)$.

Therefore, extraterrestrial radiation is thus a function of latitude, date, and time of day. [15], reported that solar radiation varies for different months and seasons likewise global solar radiation can be estimated based on coefficient of determination, cloud transmittance factor and clearness index as well.

Table 3: Descriptive statistics for Relative Humidity, minimum temperature, maximum temperature, wind speed and solar radiation.

\begin{tabular}{llcccccc}
\hline Maiduguri & 1. RH & 372 & 39.22 & 10.00 & 96.00 & 21.23 & 0.447 \\
& 2. MinT & 372 & 20.17 & 9.20 & 28.10 & 4.63 & -0.537 \\
& 3. MaxT & 372 & 35.27 & 26.10 & 42.60 & 3.34 & 0.203 \\
Ikeja & 4. Wind speed & 372 & 4.95 & 1.20 & 9.10 & 1.76 & 0.042 \\
& 5. Solar radiation & 372 & 17.21 & 8.70 & 30.60 & 3.97 & 0.293 \\
& 1. RH & 372 & 83.01 & 41.00 & 92.00 & 5.58 & -2.518 \\
& 2. MinT & 372 & 23.30 & 16.00 & 26.70 & 1.20 & -0.622 \\
& 3. MaxT & 372 & 31.10 & 25.50 & 35.30 & 1.94 & -0.200 \\
& 4. Wind speed & 372 & 4.46 & 1.60 & 9.70 & 1.37 & 0.572 \\
& 5. Solar radiation & 372 & 11.28 & 2.30 & 28.60 & 2.74 & 0.878 \\
\hline
\end{tabular}


Table 4: Correlation between the parameters

\begin{tabular}{|c|c|c|c|c|c|c|}
\hline Locations & & 1 & 2 & 3 & 4 & 5 \\
\hline \multirow{5}{*}{ Maiduguri } & 1. $\mathrm{RH}$ & 1 & & & & \\
\hline & 2. MinT & $0.526 * *$ & 1 & & & \\
\hline & 3. MaxT & $-0.316^{* *}$ & $0.526^{* *}$ & 1 & & \\
\hline & 4. Wind speed & $-0.174 * *$ & 0.095 & $0.147 *$ & 1 & \\
\hline & 5. Solar radiation & $-0.256^{* *}$ & $0.118^{*}$ & $0.343 * *$ & 0.043 & 1 \\
\hline \multirow[t]{5}{*}{ Ikeja } & 1. $\mathrm{RH}$ & 1 & & & & \\
\hline & 2. MinT & $-0.191 * *$ & 1 & & & \\
\hline & 3. $\operatorname{MaxT}$ & $-0.561 * *$ & $0.517^{* *}$ & 1 & & \\
\hline & 4. Wind speed & -0.074 & 0.094 & $-0.120 *$ & 1 & \\
\hline & 5. Solar radiation & $-0.350 * *$ & $0.410^{*}$ & $0.575 * *$ & $-0.146^{*}$ & 1 \\
\hline
\end{tabular}

The result of the correlation reveals that in Maiduguri, solar radiation was found to have a significant negative relationship with relative humidity $(\mathrm{r}=-.256$, $\mathrm{p}<0.01)$ and a significant positive relationship with minimum and maximum temperature $(\mathrm{p}<0.05)$. This means that minimum and maximum temperatures increase as solar radiation increases $(\mathrm{p}<0.05)$. Relative humidity decreases as solar radiation increases. In Ikeja, solar radiation was found to have a significant negative relationship with relative humidity $(\mathrm{r}=-.350, \mathrm{p}<0.01)$ and wind speed $(\mathrm{r}=-.146, \mathrm{p}<0.05)$ and significant positive relationship with minimum temperature $(\mathrm{r}=.410, \mathrm{p}<0.05)$ and maximum temperature $(\mathrm{r}=.575, \mathrm{p}<0.01)$. This indicates that as solar radiation increases significantly, there is a significant decrease in relative humidity and wind speed while minimum temperature and maximum temperature increases significantly as solar radiation increases significantly (Table 2). The summary result of the regression is shown in Table 3. Result in Table 3 reveals that in Maiduguri, solar radiation accounted for $6.6 \%, 1.4 \%, 3.4 \%$ and $0.2 \%$ of the variation in $\mathrm{RH}$, MinT, MaxT and wind speed whereas in Ikeja, it was $12.3 \%$, $16.8 \%, 33.0 \%$ and $2.1 \%$ respectively. The regression results were also found to be significant in both locations
( $p<0.05)$ except in Maiduguri where there was a significant regression relationship between wind speed and solar radiation. In Maiduguri, solar radiation shows significant negative effect on relative humidity $(\mathrm{t}-\mathrm{cal}$. $=$ $5.19, p=0.023 p<0.05$ ) and significant positive effect on both minimum temperature $(\mathrm{t}-\mathrm{cal} .=7.03, \mathrm{p}=0.000$, $\mathrm{p}<0.01)$ while in Ikeja, solar radiation has significant negative effect on relative humidity $(\mathrm{t}-\mathrm{cal} .=-7.189, \mathrm{p}=$ $0.000 \mathrm{p}<0.01)$ and wind speed $(\mathrm{t}-\mathrm{cal} .=-2.844, \mathrm{p}=0.005$ $\mathrm{p}<0.01)$ whereas the effect of solar radiation on minimum temperature $(\mathrm{t}-\mathrm{cal} .=8.652, \mathrm{p}=0.023 \mathrm{p}<0.01)$ and maximum temperature $(\mathrm{t}-\mathrm{cal} .=13.52, \mathrm{p}=0.000 \mathrm{p}<0.01)$ were positively significant $(\mathrm{p}<0.05)$. The standardized beta coefficients reveal that in Maiduguri, if all other variables are held constant, for every $1 \mathrm{~W} / \mathrm{m}^{2}$ increase in solar radiation, relative humidity will decrease by 0.256 and minimum temperature, maximum temperature and wind speed will increase by $0.118,0.342$ and 0.821 , respectively. For Ikeja, if other variables are held constant, for every $1 \mathrm{~W} / \mathrm{m}^{2}$ increase in solar radiation, relative humidity will decrease by 0.350 and wind speed will decrease by 0.146 while minimum temperature and maximum temperature will increase by 0.410 and 0.575 , respectively.

Table 3: Summary regression results showing the effect of solar radiation on Relative humidity, minimum temperature, maximum temperature, and wind speed.

\begin{tabular}{llllcccc}
\hline Locations & $\begin{array}{l}\text { Dependent } \\
\text { variables }\end{array}$ & r-square & Regression equation & $\boldsymbol{\beta}$ & t-cal. & P-value & F-calc. \\
\hline Maiduguri & RH & 0.066 & $\mathrm{RH}=62.819-1.371 \mathrm{~S}$ & -0.256 & 5.104 & $0.000^{* *}$ & $26.05^{* *}$ \\
& MinT & 0.014 & MinT $=17.809+0.137 \mathrm{~S}$ & 0.118 & $5.19^{*}$ & $0.023^{*}$ & $5.192^{*}$ \\
& MaxT & 0.343 & MaxT $=30.303+0.289 \mathrm{~S}$ & 0.342 & $7.03^{*}$ & $0.000^{* *}$ & $49.428^{* *}$ \\
& Wind speed & 0.002 & $\mathrm{WS}=4.624+0.019 \mathrm{~S}$ & 0.043 & 0.821 & 0.412 & 0.674 \\
& & & & & & & \\
Ikeja & RH & 0.123 & $\mathrm{RH}=91.057-0.713 \mathrm{~S}$ & -0.350 & $-7.189^{* *}$ & $0.000^{* *}$ & $51.69^{* *}$ \\
& MinT & 0.168 & MinT $=21.280+0.179 \mathrm{~S}$ & 0.410 & $8.652^{* *}$ & $0.023^{*}$ & $74.861^{* *}$ \\
& MaxT & 0.330 & MaxT $=26.523+0.406 \mathrm{~S}$ & 0.575 & $13.52^{* *}$ & $0.000^{* *}$ & $182.65^{* *}$ \\
& Wind speed & 0.021 & WS $=5.279-0.073 \mathrm{~S}$ & -0.146 & -2.844 & $0.005^{* *}$ & $8.086^{* *}$ \\
\hline
\end{tabular}

$* *$ Significant at $1 \%(P<0.01)$. ${ }^{*}$ Significant at $1 \%(P<0.05), \beta=$ standardized beta coefficient 
Table 4: Averaged monthly solar radiation, relative humidity, minimum temperature, maximum temperature, and wind speed in Maiduguri (1980-2012).

\begin{tabular}{lccccc}
\hline Month & $\begin{array}{c}\text { Solar } \\
\text { radiation(ml) }\end{array}$ & $\begin{array}{c}\text { Relative } \\
\text { humidity }(\boldsymbol{\%})\end{array}$ & $\begin{array}{c}\text { Minimum } \\
\text { temperature }\end{array}$ & $\begin{array}{c}\text { Maximum } \\
\text { temperature }\end{array}$ & Wind speed(mtrs./s) \\
\hline Jan. & 16.31 & 23.81 & 12.67 & 31.34 & 4.58 \\
Feb. & 18.07 & 17.55 & 15.60 & 34.14 & 5.53 \\
Mar. & 19.46 & 15.52 & 20.04 & 38.31 & 5.71 \\
Apr. & 19.84 & 24.29 & 23.98 & 40.56 & 5.41 \\
May & 18.58 & 39.32 & 25.85 & 39.67 & 5.42 \\
Jun. & 17.03 & 51.74 & 24.87 & 36.85 & 5.66 \\
July & 15.98 & 67.23 & 23.20 & 33.02 & 5.33 \\
Aug. & 14.77 & 74.19 & 22.53 & 31.53 & 4.40 \\
Sept. & 16.86 & 66.10 & 22.75 & 33.72 & 4.20 \\
Oct. & 17.80 & 42.35 & 21.20 & 36.31 & 4.16 \\
Nov. & 16.95 & 25.06 & 16.27 & 35.42 & 4.54 \\
Dec. & 14.90 & 23.45 & 13.12 & 32.37 & 4.44 \\
\hline
\end{tabular}

Table 5: Averaged monthly solar radiation, relative humidity, minimum temperature, maximum temperature, and wind speed in Ikeja (1980-2012).

\begin{tabular}{lccccc}
\hline Month & $\begin{array}{c}\text { Solar } \\
\text { radiation(ml) }\end{array}$ & $\begin{array}{c}\text { Relative } \\
\text { humidity } \mathbf{( \% )}\end{array}$ & $\begin{array}{c}\text { Minimum } \\
\text { temperature }\end{array}$ & $\begin{array}{c}\text { Maximum } \\
\text { temperature }\end{array}$ & Wind speed(mtrs./s) \\
\hline Jan. & 11.75 & 79.16 & 23.12 & 32.61 & 4.13 \\
Feb. & 12.88 & 78.06 & 24.14 & 33.61 & 4.53 \\
Mar. & 13.42 & 79.10 & 24.56 & 33.08 & 5.07 \\
Apr. & 13.63 & 80.16 & 24.25 & 32.35 & 5.08 \\
May & 12.22 & 83.06 & 23.64 & 31.15 & 4.32 \\
Jun. & 10.43 & 86.58 & 23.07 & 29.55 & 4.41 \\
July & 8.62 & 87.29 & 22.59 & 28.43 & 5.07 \\
Aug. & 8.17 & 86.35 & 22.29 & 28.37 & 5.33 \\
Sept. & 9.54 & 86.48 & 22.60 & 29.25 & 4.51 \\
Oct. & 10.78 & 84.90 & 22.94 & 30.55 & 3.83 \\
Nov. & 12.15 & 82.87 & 23.34 & 31.94 & 3.47 \\
Dec. & 11.73 & 82.13 & 23.05 & 32.35 & 3.73 \\
\hline
\end{tabular}
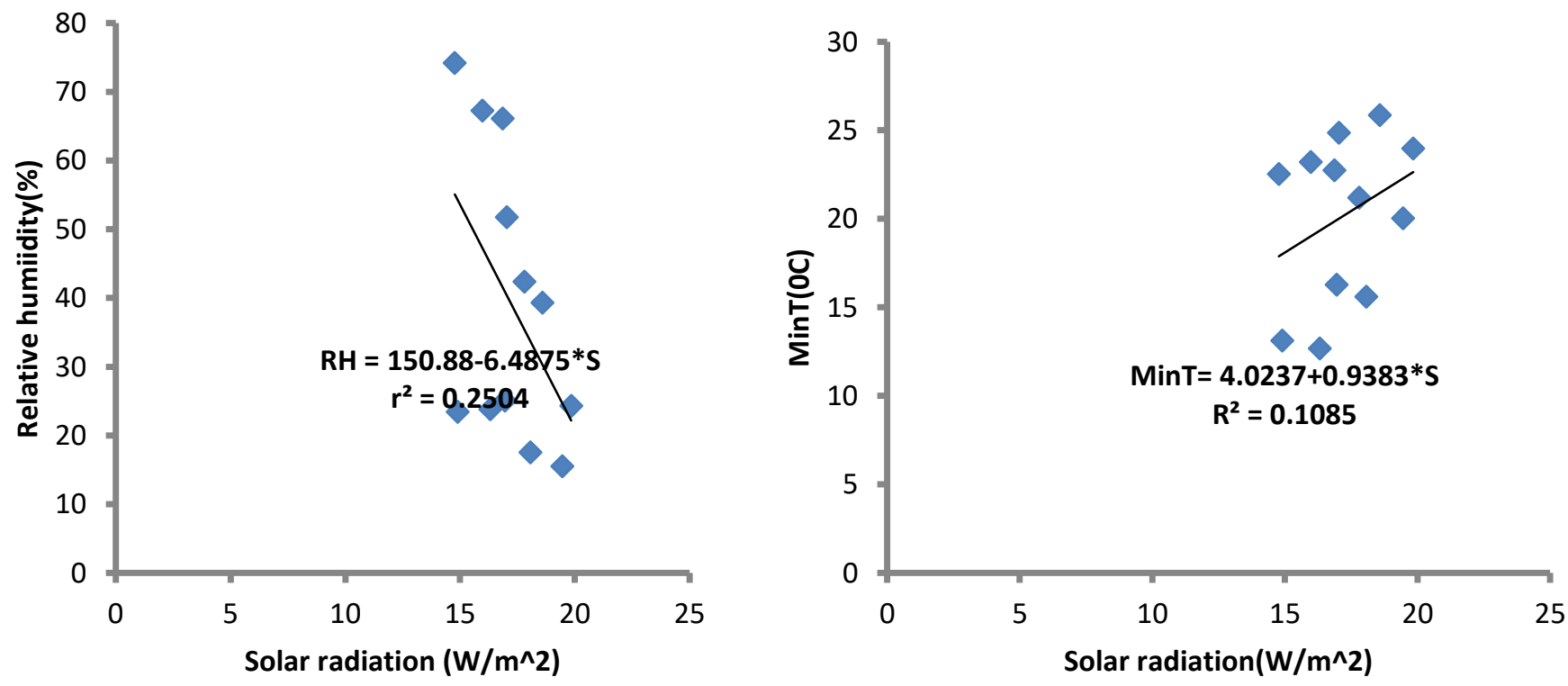

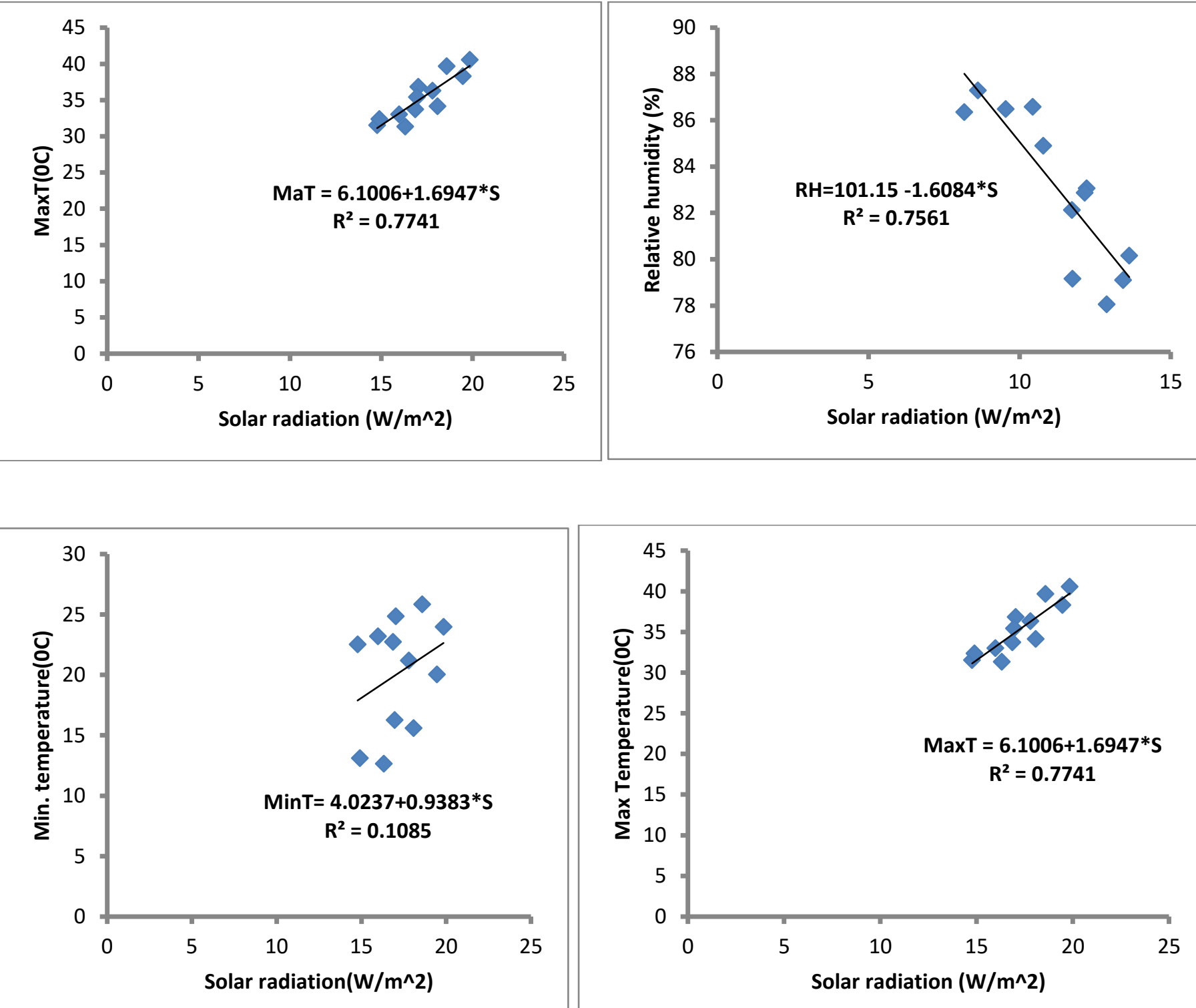

Figure 4: Regression result for averaged monthly relative humidity, wind speed and direction minimum and maximum temperature versus solar radiation in Maiduguri and Ikeja

The regression result for averaged monthly relative humidity versus solar radiation in Maiduguri shows that as solar radiation increases, relative humidity increases and that solar radiation accounted for $25.04 \%$ of the variation in relative humidity. While averaged monthly relative humidity versus solar radiation in Ikeja shows that as solar radiation increseas relative humidity in Ikeja decreases and that solar radiation accounted for $75.61 \%$ of the variation in relative humidity.

The result for averaged monthly minimum temperature versus solar radiation in Maiduguri shows that as solar radiation increases, the minimum temperatutre increases and that solar radiation accounted for $10.85 \%$ of the variation in minimum temperature. While averaged monthly minimum temperature versus solar radiation in Ikeja shows that as solar radiation incresaes, the minimum temperature in Ikeja increases and that solar radiation accounted for $10.85 \%$ of the variation in minimum temperature. The result for averaged monthly maximum temperature versus solar radiation in Maiduguri shows that as solar radiation incresaes, maximum temperatutre increases and that solar radiation accounted for $77.41 \%$ of the variation in maximum tempertature. While averaged monthly maximum temperature versus solar radiation in Ikeja shows that as solar radiation incresaes, maximum temperature in Ikeja increases and that solar radiation accounted for $77.41 \%$ of the variation in maximum temperature. The result for averaged monthly wind speed versus solar radiation in Maiduguri shows that as solar radiation incresaes, wind speed increases and that solar radiation accounted for $33.24 \%$ of the variation in wind speed. While averaged monthly wind speed versus solar radiation in Ikeja shows that as solar radiation incresaes, wind speed in Ikeja increases and that solar radiation accounted for $33.24 \%$ of the variation in wind speed. 


\subsection{CONCLUSION}

Generally, it can be observed that the trend of wind speed is such that Ikeja has a higher speed than Maiduguri. This may be due to the proximity to the Ocean and hence the effect of ocean tides. As expected, humidity and minimum temperature, solar and extraterrestrial radiations were consistently higher in Maiduguri than what was observed in Ikeja. Statistical correlation reveals that, in Maiduguri, solar radiation was found to have a significant negative relationship with relative humidity. This means that minimum and maximum temperature increase as solar radiation increases. Relative humidity decreases as solar radiation increases. While in Ikeja, solar radiation was found to have a significant negative relationship with relative humidity and wind speed and significant positive relationship with minimum temperature and maximum temperature. The regression result for averaged monthly relative humidity versus solar radiation in Maiduguri shows that as solar radiation increases, relative humidity increases and that solar radiation accounted for $25.04 \%$ of the variation in relative humidity. While averaged monthly relative humidity versus solar radiation in Ikeja shows that as solar radiation incresaes, relative humidity in Ikeja decreases and that solar radiation accounted for $75.61 \%$ of the variation in relative humidity. Therefore, the more the ocean current the more energy generated. This shows that Ikeja can be a good source of energy due to its proximity to the Ocean current.

\section{REFERENCES}

[1] Allen, R.G., and Smith, M. "An update for the definition of reference Evapotranspiration". ICIO Bulletin, 43(2) (1994), 1-34.

[2] Barry, R.G., and Chorley, R.J. "Atmosphere, Weather and Climate". 3rd edition. Methuen: London, UK. (1976).

[3] Ogolo, E.O., and Adeyemi, B. "Variations and Trends of Some Meteorological Parameters at Ibadan, Nigeria". The Pacific Journal of Science and Technology. 10(2), (2009), 981 - 987.

[4] Aweda, F.O., Akinpelu, J., Falaiye, O., and Adegboye JO. "Temperature Performance Evaluation of Parabolic Dishes Covered With Different Materials in Iwo, Nigeria. Osun State, Nigeria". Nigerian Journal of Basic and Applied Science, 24(1), (2016), 90-97.

[5] Ayoade, J.O. "Introduction to the Tropics". Spectrum Books Ltd.: Lagos, Nigeria. (1993).

[6] Alexander, L.V., Zhang, X., Peterson, T.C., Caesar, J., Gleason, B., Klein Tank, A.M.G., Haylock, M., Collins, D., Trewin, B., Rahimzadeh, F. and Tagipour, A. "Global observed changes in daily climate extremes of temperature and precipitation". Journal of Geophysical Research: Atmospheres, 111(5), (2006),1-22.
[7] Wild, M. "Global dimming and brightening: A review." Journal of Geophysical Research: Atmospheres 114(12), (2009), 1-31.

[8] Dinpashoh, Y., Jahanbakhsh-Asl, S., Rasouli, A.A, Foroughi, M., and Singh, V.P. "Impact of climate change on potential evapotranspiration (case study: west and NW of Iran)". Theoretical and Applied Climatology, 136(1), (2019), 185-201.

[9] Xiao, M., Yu, Z., Cui, Y. Evaluation and estimation of daily global solar radiation from the estimated direct and diffuse solar radiation. Theoretical and Applied Climatology, 140(3-4), (2020), 983-992.

[10] Guo, D., Westra, S., and Maier, H.R. "Sensitivity of potential evapotranspiration to changes in climate variables for different Australian climatic zones." Hydrology and Earth System Sciences, 21(4), (2017), 2107-2126.

[11] Djaman, K., L. Diop, and K. Koudahe. "Evaluation of temperature-based solar radiation models and their impact on Penman-Monteith reference evapotranspiration in a semiarid climate." International Journal of Hydrology, 4(2 (2020), 84-95.

[12] Leng, G., Zhang, X., Huang, M., Asrar, G.R., and Leung, L.R. "The role of climate covariability on crop yields in the conterminous United States." Scientific Reports, 6(1), (2016), 1-11.

[13] Zhang, J., Zhao, L., Deng, S., Xu, W., and Zhang, Y. "A critical review of the models used to estimate solar radiation". Renewable and Sustainable Energy Reviews, 70, (2017), 314-329.

[14] Fan J, Wu L, Zhang F, Cai H, Ma X, Bai H. Evaluation and development of empirical models for estimating daily and monthly mean daily diffuse horizontal solar radiation for different climatic regions of China. Renewable and Sustainable Energy Reviews, 105, (2019), 168-186.

[15] Rim C-S. "A sensitivity and error analysis for the penman evapotranspiration model." KSCE Journal of Civil Engineering, 8(2), (2004), 249-254.Amadi, S.O, Chigbu T. Variations and Trends of Some Meteorological Parameters at Ibadan, Nigeria . Int J Pure Appl Sci Technol. 2014;25(2):36-45.

[17] Willoughby AA, Aro TO, Owolabi IE. Seasonal variations of radio refractivity gradients in Nigeria. $\mathrm{J}$ Atmos Solar-Terrestrial Phys. 2002;64(4):417-25.

[18] Spencer, J. W. Fourier series representation of the position of the Sun. Search. 1971; 2 (5), 172.

[19] Iqbal M. An Introduction to Solar Radiation [Internet]. An Introduction to Solar Radiation. 1983. 335-373 http://www.sciencedirect.com/science/article/pii/B97 80123737502500173

[20] Giles, B.D. and Flocas, A.A. Air Temperature Variation in Greece, part 1: Persistence, Trend and Fluctuation. Journal of Climatology. 1984; 4:541-546 
[21] Olaniran, O.J. and Sumner, G.N. A Study of Climatic Variability in Nigeria Based on the Onset, Retreat, and Length of the Rainy Season. Int. Journal of Climatology. 1989; 9:253-269.

[22] Mitchell, J.M., Dzerdzeevskii, B., Flohn H., Hofmey, W.L., Lamb, H.H., Rao, K.N., and Wallen, C.C. Climate Change. World Meteorological Organization, Geneva, Switzerland. WMO Tech. Note 1966; 79, 80pp

[23] Hutschinson, P. Rainfall Analysis of the Sahellian Drought in Gambia. J. Climatol. 1985; 5:665-672
[24] Subbaramaya, I. and Bhanu Kumar, O. S. R. Variation of the Onset of the Summer Monsoon over India. Meteorol. Mag. 1987; 116:309-317.

[25] Fao. Chapter 3 - Meteorological data. Webpage. 2013. $\mathrm{p}$. $1-39$. http://www.fao.org/docrep/x0490e/x0490e07.htm

[26] Khem N. P., Binod K. B., Balkrishna S, Berit K. (2012). Estimation of Global Solar Radiation Using Clearness Index and Cloud Transmittance Factor at Trans-Himalayan Region in Nepal. Energy and Power Engineering, 2012, 4, 415-421. 